\title{
Europawahl 2009: Warum es sich lohnt, seine Stimme abzugeben
}

Am 7. Juni 2009 finden in Deutschland, ebenso wie in den meisten anderen Mitgliedstaaten der Europäischen Union (EU), Wahlen zum Europäischen Parlament statt. Doch wie bei den vergangenen sechs Wahlterminen seit 1979 ist das Interesse bei Wählern, Parteien und Medien quer durch Europa gering. In Deutschland kommt den Europawahlen traditionell in etwa die Bedeutung von Landtagswahlen zu. Ihr politisches Gewicht wird allgemein als niedrig eingestuft. Die Parteien treten mit farblosen Kandidaten an und führen einen wenig engagierten Wahlkampf, der sich vorwiegend um nationale Themen dreht. Auch das Medieninteresse ist begrenzt, und am Wahltag finden üblicherweise deutlich weniger Wahlberechtigte den Weg zur Urne als bei Bundestagswahlen. Bei der letzten Europawahl 2004 war die Wahlbeteiligung mit 43 \% nur etwas mehr als halb so hoch wie bei der darauffolgenden Bundestagswahl.

Kurz vor dem Wahltermin deutet alles darauf hin, dass sich dieses Schauspiel erneut wiederholen wird. So werden wohl auch dieses Mal wieder viele Wahlberechtigte zu Hause bleiben. Und die wenigen, die doch zur Wahl gehen, werden ihre Stimme vorwiegend mit dem Ziel abgeben, der Bundesregierung im Vorfeld der bevorstehenden Bundestagswahl einen Denkzettel zu verpassen. Damit steht zu befürchten, dass die Deutschen erneut die Gelegenheit ungenutzt verstreichen lassen, die Richtung der europäischen Politik durch gezielte Stimmabgabe bei den Europawahlen zu beeinflussen. Denn in Wirklichkeit ist die Frage, wer im Europäischen Parlament sitzt, politisch weit wichtiger als es der eigentümliche Umgang nationaler Parteien mit diesem Thema vermuten ließe.

Erstens kommt dem Europäischen Parlament eine zentrale Stellung im europäischen Gesetzgebungsprozess zu. Seine legislativen Kompetenzen wurden seit den 1980er Jahren bei jeder Vertragsreform ausgeweitet. Experten wie der britische Politikwissenschaftler Simon Hix halten das Europäische Parlament sogar für eines der mächtigsten Gesetzgebungsorgane der Welt. Dass dieses Urteil nicht ganz unberechtigt ist, lässt sich am Beispiel der umstrittenen Dienstleistungsrichtlinie zeigen. Der marktradikale Entwurf der Kommission sah vor, dass Dienstleistungen in Europa nach dem Herkunftslandprinzip angeboten werden sollten. Das hätte bedeutet, dass polnische oder rumänische Firmen ihre Dienstleistungen in ganz Europa gemäß den niedrigen gesetzlichen und tarifvertraglichen Bedingungen ihres Heimatlandes offerieren könnten, wodurch deutsche oder schwedische Arbeitnehmerrechte und Tarifverträge ausgehebelt worden wären. Dank der Intervention des Parlaments wurde dieses Prinzip gestrichen, sodass die verabschiedete Richtlinie gewerkschaftlichen Anliegen wesentlich stärker Rechnung trägt als die erste Version.

Zweitens geht es bei der Europawahl indirekt auch um die Bestellung des nächsten Chefs und der Mitglieder der Europäischen
Kommission. Da die Kommission über das alleinige Recht der Gesetzesinitiative verfügt und somit eine zentrale Rolle im EUGesetzgebungsprozess spielt, hat die Frage, wer Präsident dieses Organs wird und wer welche Sachressorts übernimmt, direkte Auswirkungen auf die Politik der EU. Ob der amtierende Kommissionspräsident José Manuel Barroso, der von der christdemokratisch-konservativen EVP-Fraktion (Fraktion der Europäischen Volkspartei) im Europaparlament unterstützt wird, seine Funktion für weitere fünf Jahre fortführen kann oder von einem möglichen Alternativkandidaten der europäischen Sozialdemokratie abgelöst wird, hängt auch von den Mehrheitsverhältnissen im nächsten Europaparlament ab. Die Staats- und Regierungschefs der Mitgliedstaaten haben zwar das Vorschlagsrecht, doch das Europäische Parlament muss den nominierten Kandidaten per Mehrheitsvotum bestätigen. Gerade der Wahlausgang im größten Mitgliedsland Deutschland, das zugleich das größte Kontingent an Europaabgeordneten entsendet, könnte das entscheidende Zünglein an der Waage sein. Wer am 7. Juni also seine Stimme abgibt, kann damit auch für oder gegen die Politik der amtierenden Kommission und ihres Präsidenten Stellung beziehen.

Auch die Besetzung der einzelnen Kommissare kann vom Europäischen Parlament beeinflusst werden. Zwar kommt dabei auch den nationalen Regierungen eine wichtige Rolle zu, da jede Regierung einen Kandidaten nominieren kann. Am Ende muss sich die gesamte Kommission jedoch dem Votum des Europäischen Parlaments stellen. Im Vorfeld führt das Parlament dazu Anhörungen der einzelnen Kandidaten durch. Dass dem Parlament dabei durchaus politisches Gewicht zukommt, zeigte sich bei der Bestellung der letzten Kommission 2004, als der erzkonservative italienische Kandidat Rocco Butiglione, der bei der parlamentarischen Anhörung durch homophobe Äußerungen negativ aufgefallen war, seine Kandidatur auf Druck des Parlaments zurückzog und durch einen anderen italienischen Politiker ersetzt wurde.

Ohne entsprechende Mehrheiten im Parlament sind solche gezielten Interventionen in die europäische Politik allerdings nicht möglich. Gerade wer das Feld der Europapolitik nicht den Anhängern des Marktliberalismus überlassen will, täte daher gut daran, am 7. Juni zur Europawahl zu gehen.

\footnotetext{
Dr. Oliver Treib ist Leiter der Abteilung Politikwissenschaft am Institut für Höhere Studien in Wien. Arbeitsschwerpunkte: Beziehungen zwischen europäischer und nationaler Politik, politische Parteien, Konfliktlinien in europäischen und internationalen Verhandlungen, EU-Policy-Forschung. e-mail: treib@ihs.ac.at
} 